\title{
GRAÇA GRAÚNA: A POESIA COMO ESTRATÉGIA DE SOBREVIVÊNCIA
}

\author{
Rita Olivieri-Godet ${ }^{1}$
}

\begin{abstract}
Resumo: No seio dos debates sobre o transculturalismo, na literatura, analisamos as construções poéticas das paisagens urbanas, relacionando-as às imagens da memória do território indígena e aos referentes culturais associados em Tear da Palavra (2007) de Graça Graúna. Trata-se de explorar as relações do sujeito poético com o espaço urbano e com os territórios autóctones, levando em consideração a complexidade das figurações que se referem tanto ao processo de interação entre a dimensão espacial e o ser humano, quanto às práticas do espaço e das paisagens. Observamos igualmente as mudanças da paisagem operadas pelas mobilidades forçadas, presentificadas pelos sujeitos poéticos, conforme essas paisagens remetam ao espaço urbano ou a territórios culturais tradicionais. Abordaremos a forma como a autora percebe e representa, em sua obra, a experiência individual e coletiva desses espaços. Os textos de Graúna ultrapassam a dimensão nacional e espelham as problemáticas referentes à ocupação dos territórios dos povos autóctones, inscrevendo-se em um patamar de identidade mais continental, com a reconstrução das identidades emancipadoras na contemporaneidade pluricultural das Américas.
\end{abstract}

Palavras-chave: Literatura indígena. Graça Graúna. Entre-lugar.

\section{GRAÇA GRAÚNA: POETRY AS A SURVIVAL STRATEGY}

\begin{abstract}
Taking into account the debates pertaining to transculturalism in literature, we are going to analyze the poetic constructions of urban landscapes and connect them to the images of the memories linked to indigenous territories and to cultural reference in Tear da Palavra (2007) by Graça Grauna. We will explore the relations of the poetic subject with urban spaces and indigenous territories, taking into account the complexity of figures which refer to interaction processes between the spatial dimension and the human subject linked to the use of space and landscapes. We will also explore the change in landscapes as they are produced by forced migrations as they are presented by poetic subjects, in comparison with urban spaces or with traditional cultural territories. Our perspective on the form will be linked to how the author perceives and represents the individual and collective experiences of these spaces in her work. Grauna's texts go beyond the national and expand towards different problematic, which are linked to the occupation of territories by indigenous peoples. Hence, this book is connected with a
\end{abstract}

\footnotetext{
${ }^{1}$ Université Rennes 2 / Institut Universitaire de France.
} 
blending of continental identities and a reconstruction of emancipatory identities in the context of a pluricultural contemporaneity pertaining to the Americas.

Key words: Indigenous Literature. Graça Graúna. In-between.

Para o exilado, os hábitos de vida, expressão ou atividade no novo ambiente ocorrem inevitavelmente contra o pano de fundo da memória dessas coisas em outro ambiente. Assim, ambos os ambientes são vívidos, reais, ocorrem juntos como no contraponto. Edward Said, Reflexões sobre o Exílio, 2000

Graça Graúna é o nome artístico de Maria das Graças Ferreira, nascida em 1948, na cidadezinha de São José do Campestre, no Rio Grande do Norte. Mestiça de ascendência potiguara que vive em meio urbano, Graça Graúna também é professora universitária e ensaísta, tendo escrito a primeira obra crítica consagrada à literatura indígena no Brasil. Seu percurso literário se volta para a reapropriação de suas referências culturais ameríndias, buscando uma reterritorialização simbólica. Então, como se reconstruir culturalmente indígena e reativar sua cultura, após séculos de esquecimento? É a essa questão que a criação literária de Graça Graúna começa a responder. Ela orientará nossa leitura da sua coletânea de poemas Tear da Palavra (2007), cujas construções poéticas relacionam paisagens urbanas à memória do território indígena, para investir melhor a reconstrução das identidades emancipadoras na contemporaneidade pluricultural do continente americano.

Analisamos as construções poéticas das paisagens urbanas, relacionando-as às imagens da memória do território indígena e aos referentes culturais associados em Tear da Palavra (2007). Trata-se de explorar as relações do sujeito poético com o espaço urbano e com os territórios autóctones, levando em consideração a complexidade das figurações que se referem tanto ao processo de interação entre a dimensão espacial e o ser humano, quanto às práticas do espaço e das paisagens e à relação com as mudanças da paisagem e com as mobilidades forçadas, presentificada pelos sujeitos poéticos, conforme essas paisagens remetam ao espaço urbano ou a territórios culturais tradicionais. Abordaremos a forma como a autora percebe e representa, em sua obra, a experiência individual e coletiva desses espaços. 
Partimos do princípio de que as produções literárias ameríndias se inserem no movimento de uma poética da alteridade, característica das escritas migrantes, nas quais a experiência do espaço ocupa um lugar central. É através da experiência do espaço, frequentemente tomado como metonímia da nação ou do Ocidente, que o personagem do ameríndio, o "estrangeiro de dentro", questiona seu lugar. As escritas indígenas contemporâneas, tal como as migrantes, também estão em movimento, pois se abrem ao cruzamento de culturas que buscam superar a fratura colonial e se inserem no processo de transculturalidade contemporânea que engendra novas formas de percepção do real e de expressão artística, sem renunciar, no entanto, a expor os sofrimentos do desenraizamento imposto pela colonização. Essa tensão entre o desejo de transpor a linha de fratura que a memória da expropriação desperta e a busca de relação é uma das constantes dessa produção, o que poderia talvez explicar a ambivalência presente nas obras de autores autóctones urbanos, que parecem oscilar entre uma poética do confronto (que salienta as identificações identitárias) e uma poética da relação (que promove a travessia das fronteiras). Isso nos leva a analisar a articulação entre o imaginário do espaço e as estratégias de (re)construção das identidades ameríndias na contemporaneidade.

\section{Vozes indígenas: da emergência à emancipação}

Se reconhecemos a sub-representação dos indígenas no espaço urbano brasileiro e quebequense, assim como sua sub-representação simbólica nos respectivos sistemas literários, somos obrigados a constatar que, no Quebec, a dinâmica das mobilidades culturais e das criações artísticas é mais antiga e mais intensa do que no Brasil, onde o surgimento das vozes indígenas na literatura de língua portuguesa só começa a se manifestar no fim da última década do século Xx. Duas escritoras mestiças de origem potiguara - Graça Graúna e Eliane Potiguara - assumem o papel de pioneiras nesse processo de inserção tardia da produção indígena de expressão portuguesa no sistema literário brasileiro: a primeira publicou duas coletâneas de poemas, Canto Mestizo, em 1999, e Tessituras da Terra, em 2001; a segunda publicou, 
em 2014, uma obra inclassificável, Metade cara, metade máscara², que contribuiu muito para a visibilidade do fenômeno cultural da chegada recente da literatura indígena ao mercado editorial brasileiro. Eliane Potiguara já havia publicado, em 1975, o poema "Identidade Indígena", considerado por Graça Graúna como o texto que instaurou o movimento literário indígena no Brasil, na primeira obra consagrada à literatura indígena contemporânea do país: Contrapontos da literatura indígena contemporânea no Brasil (GRAÚNA, 2013, p. 78). Contudo, é preciso admitir que a produção literária individual, em língua portuguesa, começa a alcançar certa visibilidade apenas a partir do século XXI.

No Quebec, ao contrário, desde a publicação, em 1976, de Je suis une maudite sauvagesse de An Antane Kapesh, as obras de autores ameríndios se multiplicaram. Esses textos questionam o imaginário colonizado, apresentam sua própria versão da história, resgatam os referentes da sua memória cultural, sempre questionando as relações autóctone/alóctone, o que lhes permite lançar um novo olhar sobre o Ocidente e propor um diálogo intercultural a partir de novas bases. Os autores indígenas assumem, desse modo, um lugar cada vez mais importante no cenário literário quebequense.

Tanto no Quebec quanto no Brasil, as criações indígenas literárias e artísticas são marcadas pela voz das mulheres, que ocupam uma posição central nessa produção. Essas obras trazem sua subjetividade feminina e o desejo de emancipação social e literária. É o que acontece, no Brasil, com Graça Graúna, cuja poesia manifesta o desejo de reapropriação, real e/ou simbólica, dos lugares e da memória ancestral que sobrevive na tradição oral, uma das fontes de inspiração de sua poesia.

\section{Graça Graúna: a poesia como estratégia de sobrevivência}

Mestiça de ascendência potiguara, Graça Graúna se apresenta como "Potiguar de São José do Campestre, professora na Universidade e escritora."

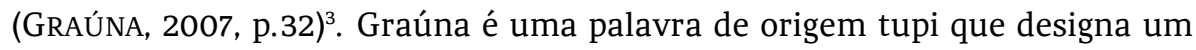

\footnotetext{
2 Ver meu artigo: Emergência das vozes ameríndias na literatura brasileira, na revista Interfaces Brasil/Canadá.

${ }^{3}$ A autora é professora e pesquisadora de literaturas e de língua portuguesa e de cultura brasileira na Universidade de Pernambuco (UPE - Campus Garanhuns). Formada em Letras, defendeu sua dissertação
} 
pássaro negro famoso pela beleza de seu canto, comum no Nordeste, inclusive na microrregião conhecida como "Agreste Potiguar"; mas "graúna" também faz referência ao célebre romance do indianismo romântico brasileiro, Iracema, de José de Alencar: nele, o autor compara a cor negra dos cabelos da bela índia Iracema à das asas da graúna. A escolha desse nome artístico remete a um desejo de ultrapassar as fronteiras identitárias essencialistas, identificando-se com dois territórios: o da experiência ameríndia e o do espaço simbólico da literatura, estabelecendo um diálogo com a tradição literária, particularmente com a produção do indianismo romântico.

Em seu ensaio sobre a literatura ameríndia, a autora atribui uma dimensão engajada a essa produção, associando-a aos movimentos recentes do ressurgimento dos povos autóctones do Brasil (índios ressurgidos), inclusive àquele do combate político para recuperar seus territórios. Poderíamos falar, então, de uma escrita-práxis: a escritura tomada como um espaço político de resistência e de autorreconstrução ontológica e antropológica.

\section{Territórios usurpados, reinvenção do lugar}

Recuperar os territórios tradicionais é o novo desafio do movimento indígena brasileiro, particularmente difícil no Nordeste, primeira região colonizada, onde a assimilação de longa data à sociedade nacional contribuiu para apagar os vestígios da história e da memória. De fato, as consequências funestas da colonização sobre os povos indígenas dessa região, inclusive sobre os potiguaras, remontam ao início da colonização: migração ou assimilação forçadas, massacres, submissão aos modelos impostos pelos missionários, intensificação da desocupação determinada pelos pioneiros da criação pecuária, desde o século XVII até o início do século XX (DANTAS, 1992, p. 433). A perda do seu território tradicional gerou a desestruturação da organização social e o apagamento da memória cultural, cujo sinal mais evidente é o desaparecimento da sua língua.

Nesse contexto, mais uma vez surge a questão: como se reconstruir culturalmente e reativar sua cultura, após séculos de esquecimento? Duas

de Mestrado sobre os mitos indígenas na literatura infantil brasileira e sua tese de Doutorado sobre a literatura indígena contemporânea no Brasil. (REBRA, Rede de Escritoras Brasileiras). 
escritoras indígenas pioneiras, Graça Graúna e Eliana Potiguara, expropriadas do território geocultural de seus ancestrais, aceitam esse desafio, reinventando novas modalidades de habitabilidade psíquica (HAREL, 2005). Elas reconfiguram, por via da criação literária, sua relação com um meio que não conheceram diretamente: "Eu não tenho minha aldeia / Minha aldeia é minha casa espiritual / Deixada pelos meus pais e avós / A maior herança indígena. / Essa casa espiritual / É onde vivo desde a mais tenra idade."4, escreve Eliane Potiguara.

A adesão de Graça Graúna a essa perspectiva se manifesta particularmente em sua coletânea de poemas, Tear da Palavra (2007), e em seu ensaio crítico, quando afirma que "o universo simbólico subsiste nas comunidades mestiças". O sentimento de perda e de expropriação originaria a escrita indígena, que não pode ser dissociada dos deslocamentos impostos aos povos autóctones (GRAÚNA, 2013, p. 57). No cerne do pensamento da autora está a ideia de que escrita e deslocamento são inseparáveis na produção literária indígena, tanto pela conexão simbólica e ontológica que esta estabelece com as origens, buscando preencher as lacunas da memória, quanto pelas interações permanentes que é levada a operar com outras culturas e que configuram seu caráter hibrido. A escrita é vista, portanto, como lugar de reconstrução identitária sensível ao outro e, ao mesmo tempo, como resiliência; tanto relação quanto confronto, o lugar reservado ao escritor é aquele do entre-lugar. "De um lado/a palavra/do outro/o silêncio/estreando realidades conhecidas. /A pá lavra o abismo/que vai de mim/ao outro"s.

O conceito de entre-lugar, que corresponde a uma forma de "cortevínculo", ajuda-nos a compreender a experiência complexa, contraditória e dolorosa da expropriação e a necessidade de reocupação expressa na poesia de Graça Graúna.

A dimensão ontológica de sua poesia aparece claramente nos textos metapoéticos da coletânea Tear da Palavra. Consubstancial ao ser, a poesia abriria as portas a um lugar de invenção de si:

Na urdidura do tempo

O ser

${ }^{4}$ Potiguara, 2004, Eu não tenho minha aldeia, p. 130.

${ }^{5}$ Graúna, Entre-lugar, 2007, p. 20. 
A poesia:

água que eu bebo

chão que me deito

ar que respiro. (“Tear da palavra”, p. 13)

É através da poesia que o sujeito poético tem acesso à vida, à sua natureza íntima e profunda, à sua relação com o mundo. A onipresença da metáfora do ato de tecer (memórias, auto-histórias, alteridades) na obra poética de Graça Graúna remete ao lugar íntimo da experiência do instante, que é igualmente aquele do compartilhamento da experiência no tempo que se escoa: o vínculo entre criação e memória abre caminho para a reconstrução identitária pela reaproximação do íntimo e do social. Considerada como uma "ponte entre mundos apartados"6, a sua poesia se abre para o outro, em um esforço de desconstrução de todo tipo de fronteiras - culturais, políticas, étnicas, sociais.

A poesia é, igualmente, um lugar de combate para abalar o imaginário sobre as culturas e os povos autóctones. O discurso poético de Graça Graúna é permeado por referências à história da violência contra os índios e à memória dos saberes ancestrais. Esses elementos forjam a base da resiliência e da utopia que emergem de sua poesia: "a literatura indígena contemporânea é um lugar utópico (de sobrevivência)”, afirma (GRAÚNA, 2013, p. 15). Ela busca transpor o abismo existente entre a memória indígena da expropriação e o esquecimento ao qual a ordem social ocidental a condenou. No entanto, a escritora não se limita a uma escrita étnica, pelo contrário. Embora as relações conflituosas entre o universo indígena e o mundo ocidental estejam no centro dessa produção, a poesia de Graça Graúna se mostra também solidária de outras vítimas do poder hegemônico ocidental. Nesse sentido, em sua obra crítica, a autora ressalta a importância do caráter transversal da literatura indígena contemporânea no Brasil, que estabelece um diálogo interétnico com outros povos excluídos (afrodescendentes) e que manifesta solidariedade pelas pessoas que sofrem a miséria e a exclusão social (trabalhadores rurais sem-terra) ou política (vítimas das ditaduras latinoamericanas): “Apesar de las fronteras / las carceles se quebrantan. /!Mira! En mi terra mestiza / un pájaro de América canta.” (Canto mestizo, p. 33). Essa

${ }^{6}$ Graúna, Tessitura, 2007, p. 18. "Ser todo coração, / enquanto houver poesia: / esta ponte entre mundos apartados". 
transversalidade reivindicada se volta ainda para a tradição literária ocidental, como mostra um fragmento de seu ensaio crítico:

Gerando a sua própria teoria, a literatura escrita dos povos indígenas no Brasil pede que se leiam as várias faces de sua transversalidade, a começar pela estreita relação que mantém com a literatura de tradição oral, com a história de outras nações excluídas (as nações africanas, por exemplo), com a mescla cultural e outros aspectos fronteiriços que se manifestam na literatura estrangeira e, acentuadamente, no cenário da literatura nacional. (GRAÚNA, 2013, p. 19)

A poesia de Graça Graúna instaura um diálogo multiétnico que conforma seu caráter híbrido, inclusive em sua escolha de usar várias línguas: português, espanhol e inglês. Como não pode se expressar na língua de seus ancestrais, seus poemas são marcados por elementos lexicais de línguas indígenas.

\section{Paisagens urbanas e memória do território}

Na obra de Graça Graúna, a interação entre a dimensão espacial e o ser humano é atravessada pela temporalidade história que traz as marcas da inscrição do ser humano na natureza. A relação que liga sua poesia ao espaço social é marcada pela figuração de uma realidade material que remete à forma como o homem organizou e transformou o espaço, alterando os referentes que constituíam a identidade dos lugares. Assim, a história se inscreve na paisagem, elemento revelador das práticas sociais que conformam o território. Essa perspectiva se origina em uma abordagem da paisagem que considera sua dimensão objetiva, noção operatória que procede pela interpretação das "dinâmicas paisagistas" que procuram elucidar o "projeto da sociedade que produziu essas paisagens” (BESSE, 2009, p. 36). Porém, a relação subjetiva com o espaço também surge em sua poesia, quando ela incorpora a cosmologia indígena que exclui a polarização entre os mundos humano e nãohumano.

Certos poemas que trabalham a figuração do espaço social representam realidades regionais e continentais reféns de um projeto de sociedade submetido à ordem socioeconômica do capitalismo ocidental. O poema Serra do Mar(GRAÚNA, 2007, p. 23) é um exemplo disso:

A história foi se formando na paisagem: 


\author{
Nem poluição \\ Nem violência nas ruas \\ nem jogos sofisticados \\ nem roupas de grife \\ barulho nenhum de automóvel \\ só a voracidade do vento \\ passando por lá.
}

O espaço de referência representado é o da Serra do Mar, cadeia de montanhas que se estende ao longo do litoral atlântico, desde o Espírito Santo até o sul de Santa Catarina. Para captá-lo, duas imagens se sobrepõem: uma delas traz a topografia e a paisagem natural sem a intervenção do ser humano; a outra retrata a paisagem cultural do meio urbano, modelada pela intervenção humana. O sujeito poético escolhe inscrever na paisagem elementos de mudanças culturais dadas como disfóricas (poluição, violência, automóveis). A rejeição a esses elementos é destacada pelo recurso anafórico, traduzindo o desejo de inscrever outra história no intervalo entre duas imagens. O corpo do poema é concebido como uma ilustração do que é anunciado no primeiro verso, ou seja, as marcas da história ancorada na paisagem. Passando de uma formulação à outra, o ponto de vista do sujeito poético muda: da percepção pessimista dos lugares onde a história se desenrola ao questionamento metafísico. Ainda assim, a imagem resultante é a da complexidade espacial que nos convida a refletir sobre o destino dos ambientes naturais e sobre os modos de vida oferecidos pelo modelo urbano ocidental.

Outro poema - Era uma vez (GRAÚNA, 2007, p. 31) -, explora a memória do território brasileiro, desde o contexto da aculturação colonizadora até o presente, retraçando as transformações das paisagens naturais e culturais. O texto evoca o caráter conflituoso da tomada das terras indígenas pelo projeto colonizador que levou à formação do território nacional brasileiro:

\author{
Um pernil de carneiro \\ retalhado em fatias \\ aos que foram chegando \\ cada vez mais estrangeiros. \\ No vai-e-vem de troncos \\ quantas nações em prantos! \\ E os homens-daninhos \\ Seduzindo a taba. \\ Grávidos de malícia \\ sedentos de guerra \\ dançam a falsidade
}




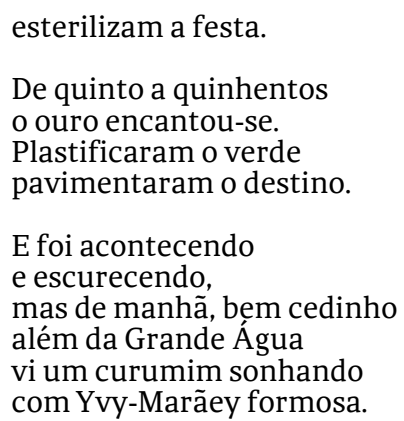

A imagem, calcada no desenho do mapa do Brasil, expressa o apetite devorador do regime colonial. O pernil retalhado em fatias remete, por sinédoque, ao mapa das sesmarias. O sistema sesmarial foi a primeira tentativa jurídica, imposta por Portugal, de tomar terras e do povoar o território da colônia. O poema desperta a memória histórica da expropriação territorial, adotando o ponto de vista dos índios para relembrar a violência do processo de ocupação do território, as guerras, o estupro das mulheres indígenas, os deslocamentos forçados, incluindo o tráfico negreiro, responsável pela deportação de toda uma população de migrantes nus (GLISSANT, 2005) para trabalhar como escravos nas terras roubadas dos povos indígenas. A dimensão histórica do poema expõe a desestruturação das sociedades tribais, enquanto destaca as mudanças radicais das paisagens e da relação com o espaço ("Plastificaram o verde / pavimentaram o destino"). Ela alude a um novo mundo sedentário, onde o plástico e o asfalto, matérias que simbolizam o meio urbano, designam outra forma de inscrição humana na natureza. O fim do poema desvia do fio macabro da história e reintroduz a esperança, recorrendo a imagens que apelam para a renovação e reintroduzem a utopia: "E foi acontecendo / e escurecendo, / mas de manhã, bem cedinho / além da Grande Água / vi um curumim sonhando / com YvyMarãey formosa.". A matéria poética busca a memória cultural indígena, fazendo brotar referências míticas e linguísticas. O poema se conclui com a imagem de uma criança indígena que sonha com a Terra sem Males, "lugar privilegiado e indestrutível, onde a terra produz seus próprios frutos e onde não se morre" (CLASTRES, 1975, p. 37). O poema se apropria das palavras proféticas do mito, sugerindo um futuro em que seria possível uma reorganização social, apesar do colapso das populações indígenas.

Os poemas que despertam a memória da formação do território da nação brasileira se inserem em uma poética de confronto, que expõe a lógica 
espacial conflituosa subjacente à apropriação do espaço das Américas, transformado em espaço de exclusão. A transversalidade reivindicada pela autora em sua obra crítica se constrói pela abertura para as populações que compartilham da experiência da exclusão no Ocidente: os ameríndios, os negros e os pobres, vítimas da precariedade material e física. Os espaços de exclusão são múltiplos, mas a cidade representa o não-lugar (AUGÉ, 1992) por excelência, metonímia do presente da história ocidental, devido à função central que ela exerce na organização da existência dos atores sociais.

Extrapolando a dimensão geográfico-espacial, alguns poemas dão à imagem da cidade um sentido simbólico negativo: "No deserto das cidades / uns cavaleiros sonham / mas sonham só / seduzidos pela mais valia." (Uns cavaleiros, p. 30). Nesse poema, o espaço da cidade é associado à esterilidade das relações humanas, à impossibilidade de fecundar outros sonhos além daquele que reflete uma ordem social e econômica excludente, que gera o abandono, a solidão "de hermanos y Hermanas / em los desiertos de la ciudad" (Canción peregrina, p. 11).

As imagens da experiência disfórica da cidade se multiplicam em textos poéticos como Cantares (p. 21), marGARIdas (p. 25) e Via-Crucis (p. 36), que trazem o espaço sombrio, opressivo e violento das ruas e das favelas habitadas por miseráveis famintos. A poesia nasce da dor que sente o sujeito poético quando toma consciência do sofrimento dos necessitados, com os quais se identifica: "A caminho do calvário / a minha gente faminta / só abocanha fartura / apetitosa em out-door" (Via-Crucis, p. 36). Contudo, como vimos, a poesia é também discurso libertador que permite ao sujeito poético resistir e tecer laços de solidariedade: "anônimas/ animas / de niñas / y niños / (perdidos en la calle) de mãos dadas" (Laços, p. 8). O poema Canción peregrina (p. 11) é um exemplo emblemático disso:

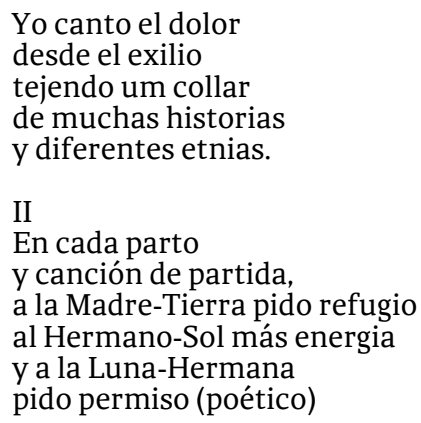




\begin{abstract}
a fin de calentar tambores
y tecer un collar

de muchas historias

y diferentes etnias.

III

Las piedras de mi collar son historia y memória del flujo del espíritu de montañas y riachos de lagos y cordilleras de hermanos y hermanas en los desiertos de la ciudad o en el seno de las florestas.

IV
\end{abstract}

Son las piedras de mi collar y los colores de mis guias: amarillo

rojo

branco

y negro

de Norte a Sur

de Este a Oeste

de Ameríndia o Latinoamérica pueblos excluídos.

$\mathrm{V}$

Yo tengo um collar

De muchas historias

y diferentes etnias.

Se no lo reconecen, paciencia.

Nosotros habemos de continuar gritando

la angustia acumulada

hace más de 500 años.

VI

Y se nos largaren al viento ?

Yo no temeré,

nosotros no temeremos.

Sí! Antes del exilio

Nuestro Hermano-Viento

Conduce nuestras alas

Al sagrado círculo

donde el amalgama del saber

de viejos y niños

hace eco em los suenos

de los excluidos.

VII

Yo tengo um collar

de muchas historias

$\mathrm{y}$ diferentes etnias.

A identificação do sujeito poético com a condição de exilado inaugura um discurso transcultural de caráter político que lhe permite reconstruir sua relação com o meio. O título - "Canción peregrina” - anuncia 
a essência cambiante de uma escrita que busca a articulação com o outro, solidarizando-se com as vítimas da expropriação territorial e dos deslocamentos forçados. Uma viagem simbólica cuja intenção é criar relações que influenciem a reconstrução das identidades individuais e coletivas, na qual a rememoração da experiência tradicional dos indígenas em sua relação com o espaço tem um papel central. Essa postura promove a liberação de um imaginário incrustado na fratura colonial, enquanto considera sua superação através da recriação de modalidades de habitabilidade psíquica que recorrem a um outro tempo, graças à persistência da transmissão memorial, e a um outro lugar, o espaço intersticial - certamente tenso, mas resiliente inaugurado pelo poema. Como afirma Daniel-Henri Pegeaux, “escrever o espaço não tange apenas ao exercício retórico [...] escrever o espaço é sempre um ato simbólico ou eufêmico de apropriação do espaço, quando esta fosse apenas verbal." (PAGEAUX, 2007, 109).

O poema é permeado de referências culturais indígenas, cuja imagem central, a do tecer do colar, retoma, por meio de uma mise en abîme, a fratura do discurso poético: "tejendo um collar / de muchas historias". Seu caráter especular aproxima o discurso poético de outros sistemas simbólicos indígenas, tanto artísticos quanto míticos, aos quais ele recorre. A escolha dessa modalidade discursiva é reforçada pela alternância, na enunciação, entre os pronomes "Yo" e "Nosotros", que destaca a identificação do "eu" escrevendo à comunidade dos excluídos, apesar das diferenças étnicas. O jogo de correspondências aparece também na evocação da experiência compartilhada do espaço continental da Ameríndia e da Latinoamérica. O imaginário do local privilegiado é o da paisagem natural, pois permite figurar a especificidade da cosmologia indígena, baseada nas interações intensas que os povos nativos mantêm com os elementos da natureza (estrofes III e VI) em relação com seu sistema de pensamento.

Outros poemas exploram as relações identidade/espaço, inspirandose em aspectos da cosmologia indígena. Por exemplo, em Poratinando, a autora se distancia da objetivação ocidental da natureza e adere a um ponto de vista ontológico que recusa a autonomia do ser em face do meio ambiente. "Sei dos segredos / dos pesadelos / da solidão / dos anseios / do pranto / das matas / dos rituais / das eras / dos mares / das lutas / das curas / das ervas. [...]" (Poratinando, p. 9). O título desse poema, no qual natureza e cultura se encontram entrelaçadas, é um neologismo derivado de "porantim", palavra 
que significa "remo", “arma” e "memória” na língua dos índios Sateré-Mavé, da Amazônia - a própria autora esclarece, em uma nota, o sentido dessa mestiçagem linguística. O eu-lírico se inspira na cosmologia dos povos indígenas para apresentar uma certa imagem do espaço americano, investido de significações íntimas, históricas e memoriais. A reconstrução identitária se dá no cruzamento da reivindicação da herança simbólica ancestral com as experiências dos espaços herdados, tanto imaginários quanto referenciais: "Sou remo, arma e memória".

A primazia da história e da memória na representação do espaço americano, característica da obra de Graça Graúna, repercute a expropriação territorial, linguística e cultural de que foram vítimas os potiguaras e outros povos autóctones. A mediação poética é considerada como uma estratégia de sobrevivência. Sua escrita cambiante busca recriar um espaço intersticial pela abertura ao outro, aos excluídos, o que dá lugar a uma poética da relação, na qual a mestiçagem cultural se torna um símbolo emblemático. As representações construídas pelo universo simbólico da autora visam à reconstrução das referências identitárias enquanto processo que se abre ao outro e nega o retraimento identitário assombrado por um impossível "retorno às origens": esses universos móveis e mestiços constituem a base de novas formas de habitabilidade psíquica. Graça Graúna reinveste uma simbólica baseada na coabitação, aberta a fenômenos de hibridação cultural, para não se deixar paralisar pela memória traumática da colonização. A autora busca também significar a resistência ao neocolonialismo atual. Com isso, sua poesia inaugura novas vias no espaço ferido das Américas:

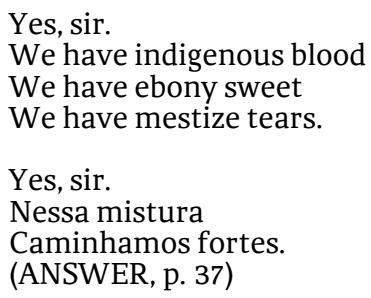

Sem mascarar as contradições, a coletânea poética de Graça Graúna tenta superá-las através do entrecruzamento simbólico dos espaços, que se anuncia como resiliência e promessa de mutação (IMBERT, apud BOUCHARD ET ANDRÈS, 2007, p. 157), enquanto elabora um discurso transcultural. 
O discurso libertado de Graça Graúna formula uma crítica aos aspectos éticos, ecológicos e políticos do sistema de pensamento responsável pelo modelo de desenvolvimento ocidental, imposto aos antigos territórios tradicionais, bem como ao meio urbano. Essa crítica cosmopolítica propõe a reformulação da relação com o território das Américas. A autora se engaja num combate pelo ressurgimento dos traços apagados da presença autóctone nas Américas, reativando a memória histórica enterrada desse continente para exigir que sua contribuição milenar seja levada em consideração na contemporaneidade. Seu discurso literário reescreve o passado para se apropriar melhor do futuro e abrir novas possibilidades de viver no mundo. Sua condição de "anfíbio", ou seja, de mulher urbana indígena que vive no entre-lugar, exposta às dimensões simultâneas da experiência da migração, seja vivenciada ou simbólica, remete tanto às perdas quanto ao lugar de vigilância que essa experiência favorece. (HAREL, 2005, p. 215).

Graça Graúna reivindica a escrita como um espaço de sobrevivência, através do qual ela se reconstrói enquanto sujeito, servindo-se das dinâmicas transculturais para inovar sua expressão literária. A escritora, por não poder se expressar na língua dos potiguaras, recorre a uma mestiçagem linguística original que imprime uma dimensão transamericana em sua poesia. A marca ambivalente que se manifesta em sua criação poética, que a faz oscilar entre a ênfase às clivagens identitárias e o desejo de conectar espaços heterogêneos, pode ser explicada pelas marcas conflituosas da história que conformam seu discurso. Este expõe as contradições, inclusive o ponto de vista dos ameríndios. Sua poesia articula uma visão política da realidade - que se manifesta através da denúncia da expropriação e do engajamento pela emancipação -, a uma concepção relacional, voltada para o futuro, baseada na troca e no compartilhamento. Sua postura instável se relaciona com sua posição de entre-Iugar. Como lembra Daniel Sibony, "no entre-lugar, não há somente abismos, há tentativas de passagem, espaços fronteiriços e precários, lugares de vida e de inviável" (SiBONY, 1991, p.7). É isso que revelam as temáticas da desagregação, da resistência, da passagem e do renascimento presentes na poesia de Graça Graúna. Seus textos poéticos rompem o imaginário colonizado no espaço das Américas, reacendendo a memória ancestral da ocupação do território pelos povos autóctones, para contribuir com a reconstrução de sua identidade emancipadora na contemporaneidade pluricultural do continente americano. 


\section{Referências}

Augé, Marc. Non-lieux. Introduction à une anthropologie de la surmodernité. Paris: Seuil, 1992.

ASSMANN, Jan. La mémoire culturelle. Paris: Aubier, 2012.

ASSMANN, Aleida. Espaços da recordação. Formas e transformações da memória cultural. Campinas/SP: Editora da Unicamp, 2011.

BERND, Zilá. Por uma estética dos vestígios memoriais. Belo Horizonte: Fino Traço, 2013.

BESSE, Jean-Marc. Le goût du monde. Exercices du paysage. Arles: Actes Sud/ENSP, 2009.

BOUCHARD, G., et ANDRES, B. Mythes et sociétés des Amériques. Montréal: Editions Québec Amérique, 2007.

CLASTRES, DANTAS, B., SAMPAIO, J. A. L., CARVALHO, M. R. G., "Os povos indígenas do Nordeste brasileiro. Um esboço histórico». In: CARNEIRO DA CUNHA, Manuela (Org.) História dos índios no Brasil. São Paulo: Cia das Letras, 1992, p. 431-456.

GAGNE, Michel, «Hochelaga». Encyclopédie Canadienne, 2015. http://www.encyclopediecanadienne.ca/fr/article/hochelaga/ (consulté le 20 mars 2017)

GAGNE, Natacha et JEROME, Laurent (sous la direction de). Jeunesses autochtones. Affirmation, innovation et résistance dans les mondes contemporains. Rennes: PUR, 2009.

GODET, Rita Olivieri. "Voz feminina ameríndia e escrita do espaço», Interfaces Brasil/Canadá, Vol 16, n 3, dezembro 2016, “À procura de novos paradigmas: estudos indígenas no Canadá e nas Américas”, Eloína Prati dos Santos, Rubelise da Cunha (dir.) https://periodicos.ufpel.edu.br/ojs2/index.php/interfaces/article/view/9386

GODET, Rita Olivieri, «L' «espace évanoui» du continent américain et l'imaginaire des confins». BOUVET, Rachel et GODET, Rita Olivieri (dir.). Géopoétique des confins. Rennes: PUR, 2018, p. 64-89.

GRANJEAN, Pernette (sous la direction de). Construction identitaire et espace. Paris: L'Harmattan, 2009.

GRAUNA, Graça. «Diálogo multiétnico: História e Memória de Negros e Índios em Toni Morrison e Vargas Llosa». 
GRAUNA, Graça. Canto Mestizo. Rio de Janeiro: Ed. Blocos, 1999.

GRAUNA, Graça. Tessituras da Terra. Belo Horizonte: Edições M.E, 2001.

GRAUNA, Graça. Tear da palavra. Belo Horizonte: S.n., 2007.

GRAUNA, Graça. Contrapontos da literatura indígena contemporânea no Brasil. Belo Horizonte: Mazza Edições, 2013.

HAREL, Simon. Braconnages identitaires. Un Québec palimpseste. Montréal: VLB, 2006.

HAREL, Simon. Les passages obligés de l'écriture migrante. Montréal: XYZ, 2004.

IMBERT, Patrick, "Les trois $\mathrm{R}$ - ruptures, route et réussite - dans les Amériques: entre l'oubli et la promesse». BOUCHARD, G., et ANDRES, B. Mythes et sociétés des Amériques. Montréal: Editions Québec Amérique, 2007, p. 139-169.

KAPESH, An Antane. Je suis une maudite sauvagesse. Ottawa: Leméac, 1976.

MORENCY, Jean. Le mythe américain dans les fictions d'Amérique. Québec: Nuit Blanche Editeur, 1994.

MORISSET, Jean. Les chiens s'entre-dévorent. Indiens, Blancs et Métis dans le Grand Nord canadien. Montréal: Mémoire d'encrier, 2009.

MORISSET Jean, «Terra Hochelaga» suivi de "L'Europe se saisit de l'Amérique», texte inédit, 2007.

PAGEAUX, Daniel-Henri. Littératures et cultures en dialogue. Paris: L'Harmattan, 2007.

REBRA, Rede de Escritoras Brasileiras, http://rebra.org/escritora/escritora_ptbr.php?id=1035 Consulté le 28/02/2017.

SIBONY, Daniel. Entre-deux. L'origine en partage. Paris: Seuil, 1991.

SIOUI, Georges E. Histoire amérindienne de l'Amérique. Québec/Paris: Les Presses de l'Université Laval/L'Harmattan, 2005.

Recebido em 30 de abril de 2018.

Aceito em 28 de maio de 2018 